\title{
Correction to: Impact of diagenetic processes on the petrophysical properties and quality of the Miocene "Reefal limestone" reservoir in Al-Hamd field, Gulf of Suez, Egypt
}

\author{
Mohamed M. Abouelhassan ${ }^{1} \cdot$ Mohamed F. Abu-Hashish ${ }^{1}$ (D) Hany M. Ashry ${ }^{2}$
}

Published online: 6 July 2021

๑ Springer-Verlag GmbH Germany, part of Springer Nature 2021

\section{Correction to: Carbonates and Evaporites (2021) 36:21 https://doi.org/10.1007/s13146-021-00685-x}

In the original publication of the article, the Fig. 19a, b, d and e were incorrectly published. The correct Fig. 19 are as follows:

The original article has been corrected.

The original article can be found online at https://doi.org/10.1007/ of cementation on carbonate rock

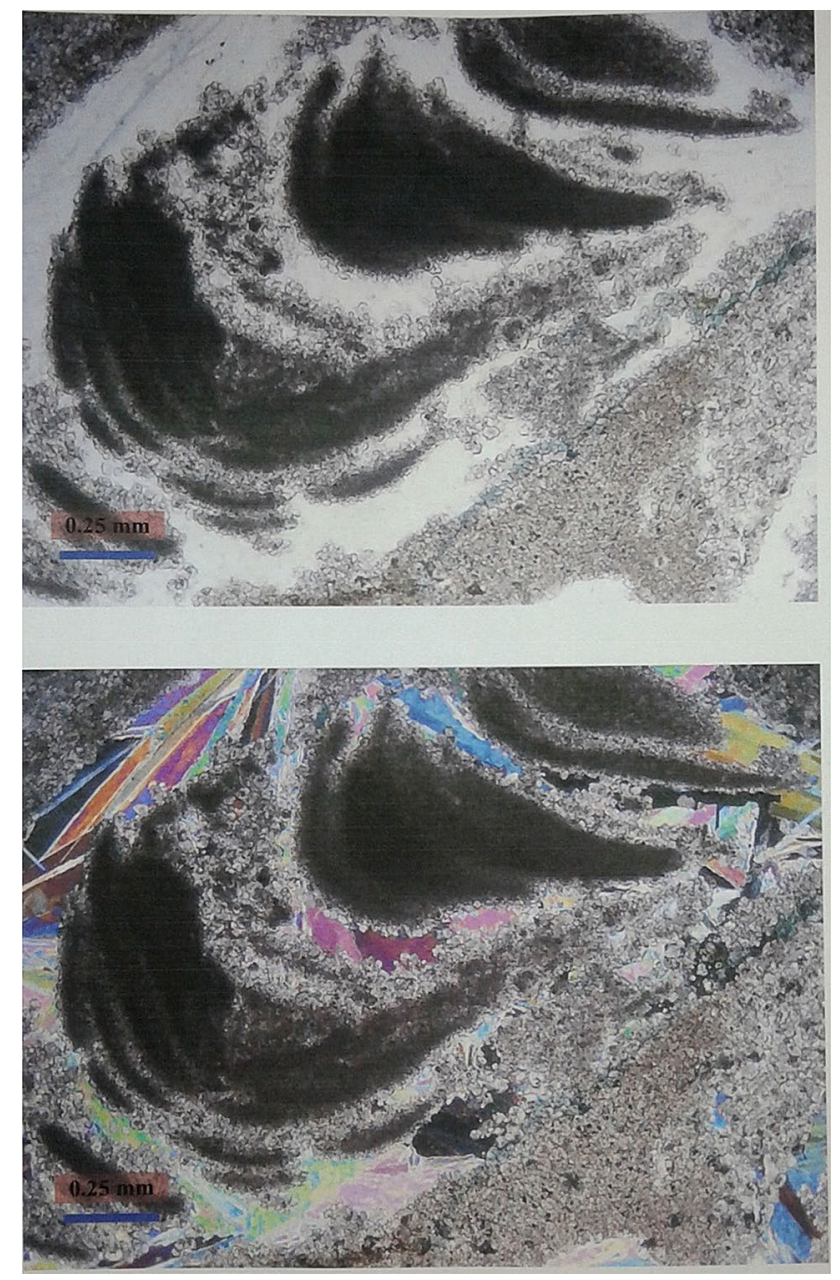

Fig. 19a: Showing presence of anhydrite as cement materials as effect

Mohamed F. Abu-Hashish

mfarouk64@gmail.com

1 Geology Department, Faculty of Science, Menoufiya University, Shebin El-Kom, Egypt

2 Egyptian General Petroleum Corporation (EGPC), Cairo, Egypt 


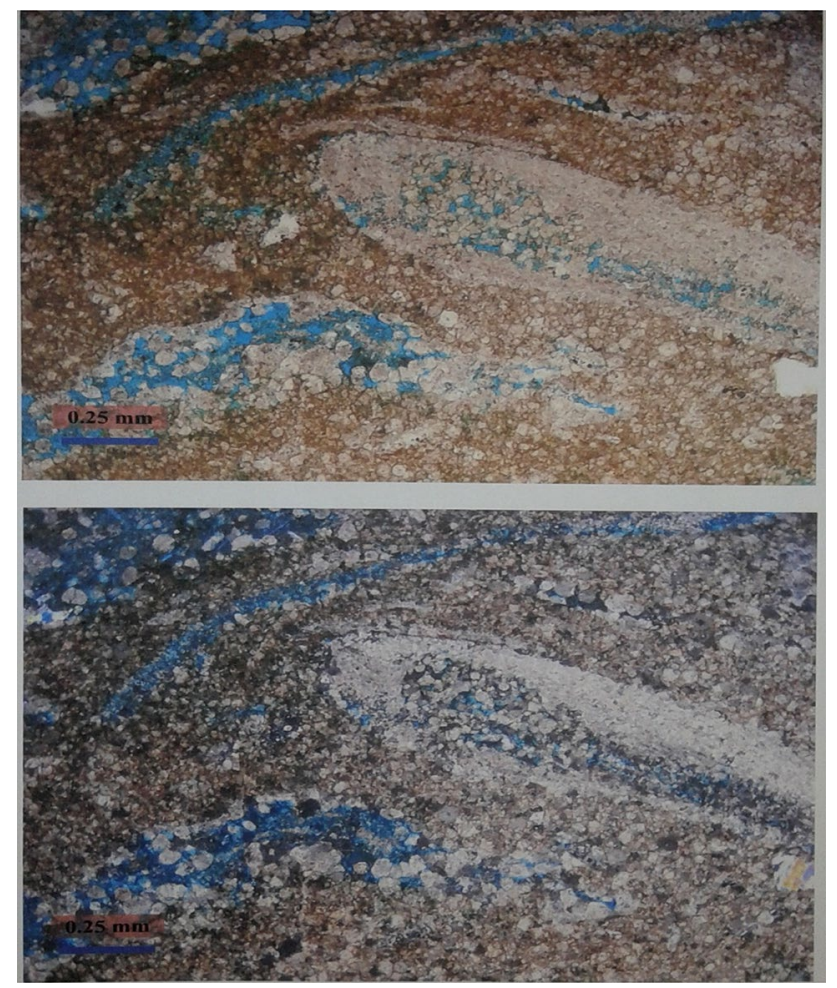

Fig. 19b: Showing some channels as the effect of dissolution process on carbonate rock
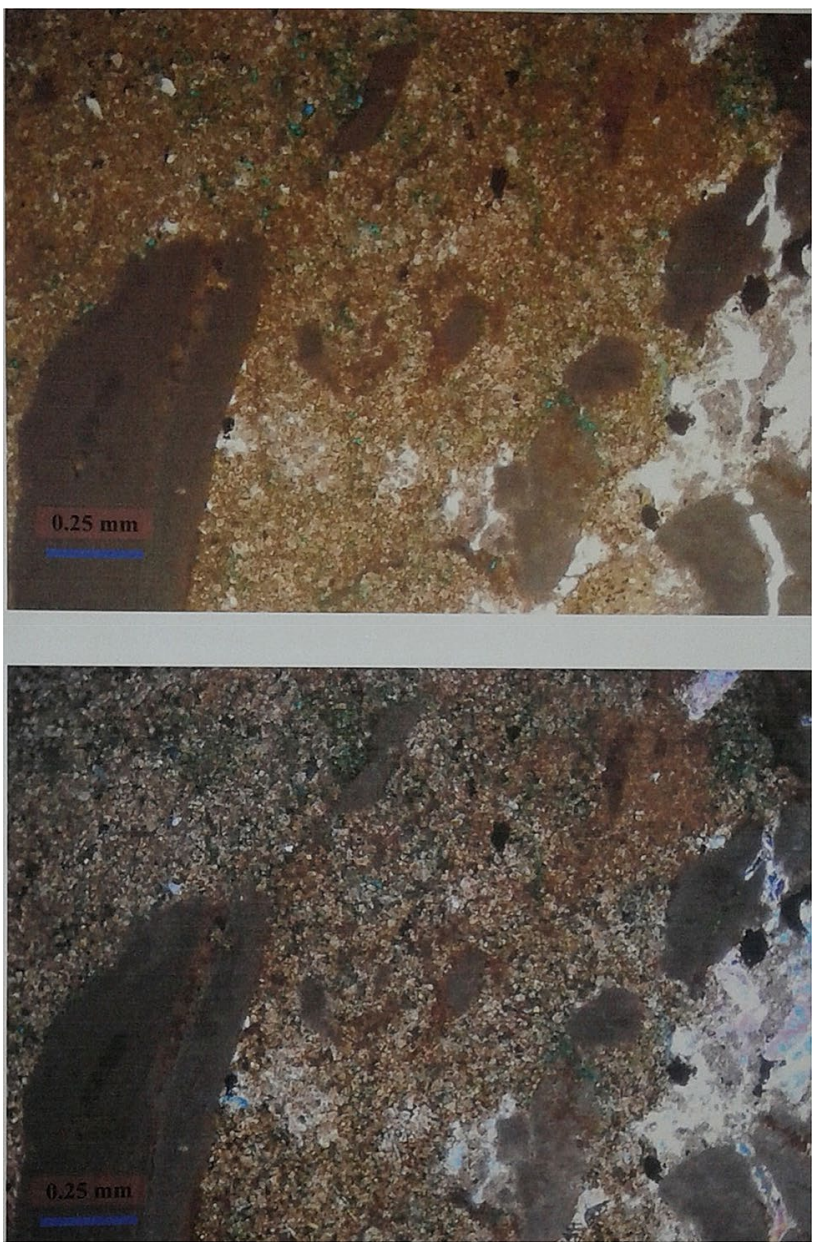

Fig. 19d: showing small to medium, dolomite crystals as effect of dolomitization process on carbonate rock 


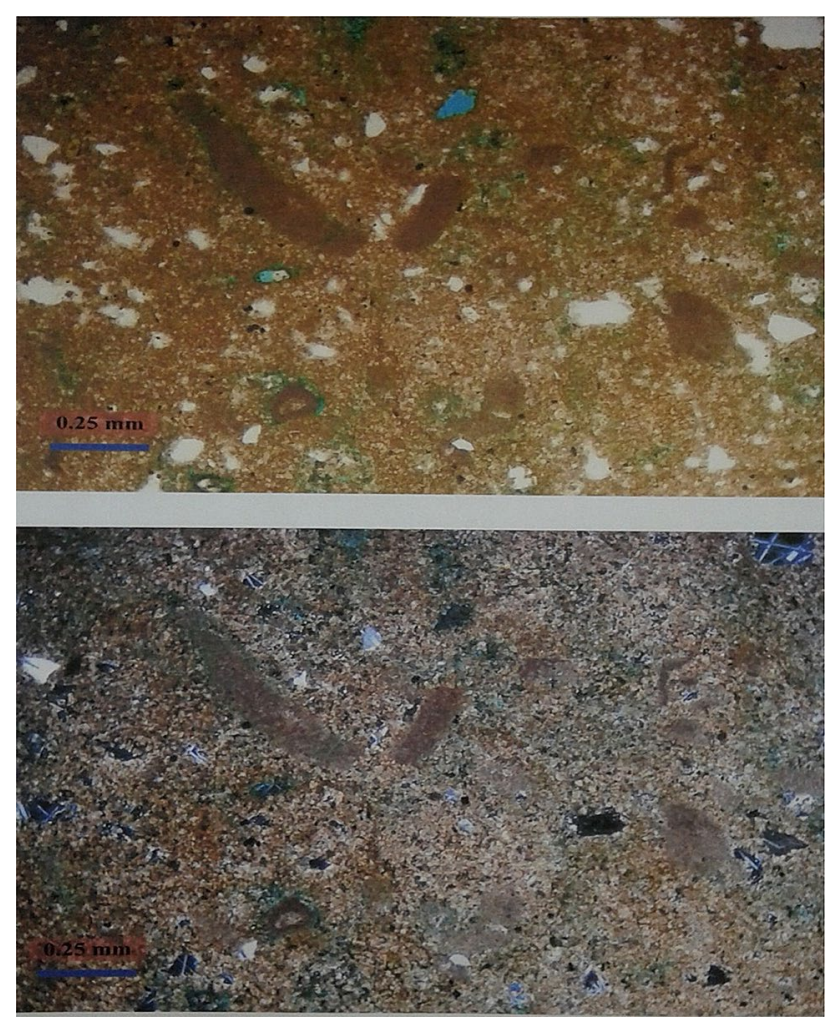

Fig. 19e: showing medium to coarse grain, silica and quartz crystals as effect of silicification process on carbonate rock

Publisher's Note Springer Nature remains neutral with regard to jurisdictional claims in published maps and institutional affiliations. 